\title{
El desafío de ser profesor universitario en tiempos de la COVID-19 en contextos de desigualdad
}

\section{The challenge of being a university professor in times of COVID-19 in contexts of inequality}

\section{O desafio de ser professor universitário em tempos de COVID-19 em contextos de desigualdade}

Karen Gajardo-Asbún

Universidad de Talca

Linares, Chile

karen.gajardo@utalca.cl

(iD https://orcid.org/0000-0003-1386-461X

Eddy Paz-Maldonado Universidad Nacional Autónoma de Honduras

Tegucigalpa, Honduras

eddy.paz@unah.edu.hn

(D) https://orcid.org/0000-0002-2324-8813

Gonzalo Salas

Universidad Católica del Maule

Talca, Chile

gsalas@ucm.cl

https://orcid.org/0000-0003-0707-8188

Lorena Alaluf

Universidad Católica del Maule

Talca, Chile

alalufg@ucm.cl

(iD) https://orcid.org/0000-0001-8671-2313

Resumen: Se reflexiona sobre lo que significa ser profesor universitario en tiempos de la COVID-19 y en contextos de desigualdad, tal es el caso de Chile y Honduras, países de donde provienen los autores de este editorial.

Palabras claves: COVID-19, enseñanza superior, profesor universitario, desigualdad.

Abstract: It reflects on what it means to be a university professor in times of COVID-19 and in contexts of inequality, such is the case of Chile and Honduras, countries where the authors of this editorial came from.

Keywords: COVID-19, higher education, university professor, inequality.

Resumo: Reflete sobre o que significa ser professor universitário em tempos de COVID-19 e em contextos de desigualdade, como é o caso do Chile e Honduras, países de onde vieram os autores deste editorial.

Palavras-chaves: COVID-19, ensino superior, professor universitário, desigualdade.

Recibido: 03/08/2020 Aceptado: 05/08/2020 
https://doi.org/10.15359/ree.24-S.14

https://www.revistas.una.ac.cr/index.php/educare

educare@una.ac.cr

\section{Introducción}

La actual crisis mundial producto de la COVID-19 ha dejado en evidencia las desigualdades educativas y ha exacerbado los niveles de pobreza en América Latina. Dichos factores impactan directamente en la Educación Superior y en todos sus actores, quienes han debido adaptarse a este nuevo escenario. En este marco, el presente Editorial pretende reflexionar sobre lo que significa ser profesor o profesora universitaria en tiempos de pandemia y en contextos de desigualdad, tal es el caso de Chile y Honduras, países donde ejercemos nuestra labor.

\section{Desarrollo}

A medida que se incrementaron los contagios y se declaraba en marzo pasado la COVID-19 como una pandemia, las autoridades chilenas y hondureñas implementaron diferentes acciones relacionadas principalmente con el distanciamiento físico por un tiempo indefinido, para mitigar la propagación del virus. Producto de ello, las universidades fueron cerradas y la educación superior tuvo que transitar, de una enseñanza presencial, a una modalidad a distancia. Este cambio transformó los aspectos laborales del profesorado universitario, dado que se intensificaron las cargas de trabajo y las jornadas educativas (Allen et al., 2020), situación que cobra gran relevancia, ya que ha puesto en resonancia el aporte que desarrollan las profesoras y los profesores universitarios, lo cual involucra por una parte, facilitar las condiciones de aprendizaje orientado a las características del estudiantado, al contexto de enseñanza y al perfil profesional que debe formar, y a su vez, ejercer actividades de investigación, gestión y extensión universitaria, dependiendo de las especificaciones de cada carga académica en particular.

La Educación Superior en nuestros países se desarrolla bajo un sistema neoliberal generador de pobreza, desigualdad y exclusión. En Chile, el 18 de octubre de 2019 se inició un estallido social contra las injusticias provocadas por dicho sistema el cual mantiene al país con una gran brecha social, económica y educativa. Por su parte, Honduras sufrió el año 2009 un golpe de estado que estableció una élite político-económica que ha impulsado medidas privatizadoras afectando el desarrollo de la educación.

La pandemia ha sacado a la luz la brecha digital, la cual ha dejado al descubierto la desigualdad presente en nuestros países y en Latinoamérica en general, observándose realidades disímiles en los universitarios, algunos de los cuales disponen de espacios de estudio, herramientas digitales, acceso a internet y muchos otros carecen de estos elementos fundamentales para cursar un semestre académico. El rol del profesorado universitario, en un gran número, ha sido relevante en el acompañamiento del estudiantado y no puede ser reemplazado. Por tanto, se coincide con otras personas autoras y se espera que esta implementación de la educación en línea no se convierta en un pretexto para sustituir al 
https://doi.org/10.15359/ree.24-S.14

profesorado por herramientas de enseñanza virtual (Corbera et al., 2020). Es necesario repensar la formación universitaria sin desvalorizar el quehacer pedagógico, dado que el rol de la docencia universitaria es determinante en impulsar el desarrollo humano.

Las profesoras y los profesores universitarios han debido asumir una serie de desafíos, entre ellos: desarrollar un proceso educativo a distancia que ha demostrado la obligatoriedad del uso de medios tecnológicos y la necesaria conectividad del estudiantado para el aprendizaje efectivo, para lo cual debe fomentarse el aprendizaje autónomo, la comunicación efectiva y la búsqueda de orientación (Mohmmed et al., 2020).

Por otra parte, un desafío latente se vincula a la emocionalidad en estudiantes, ya que muchos han tenido o han estado cerca de la enfermedad. El profesorado universitario ha desplegado una serie de esfuerzos en sus actividades docentes, sin embargo, no es para nada simple el monitoreo y seguimiento de los comportamientos del estudiantado en torno a los aprendizajes. Las estudiantes y los estudiantes han valorado la cercanía y flexibilidad de profesoras y profesores en la esperanza de promover tranquilidad en estos tiempos de incertidumbre e intensificación del flujo de información. Al mismo tiempo, el profesorado universitario ha vivenciado un proceso agotador, incierto y de múltiples cambios.

\section{Conclusión}

En conclusión, ser parte del profesorado universitario en este contexto de pandemia requiere enfrentar una serie de retos, entre los cuales se encuentra la priorización de contenidos en las cátedras, potenciar la colaboración entre estudiantes, y mitigar las dificultades de aprendizaje en un entorno digital. Además, es determinante que las políticas educativas desarrollen protocolos e incluyan un plan detallado para el futuro en situaciones de crisis y emergencias sanitarias. Finalmente, no se debe desconocer que las profesoras y los profesores universitarias han debido realizar sus cursos con una repentina transición a contextos de aprendizaje muy diversos, fuera de su hábitat natural, manteniendo la responsabilidad, el compromiso y un sentido igualitario en el ejercicio docente en contextos de desigualdad, sobre todo en el marco de las ideologías neoliberalizadoras de nuestras naciones.

Nota general: Corrección de estilo y traducciones a cargo de las personas autoras. 
https://doi.org/10.15359/ree.24-S.14

https://www.revistas.una.ac.cr/index.php/educare

educare@una.ac.cr

\section{Referencias}

Allen, J., Rowan, L. y Singh, P. (2020). Teaching and teacher education in the time of COVID-19. Asia-Pacific Journal of Teacher Education, 48(3), 233-236. https://doi.org/10.1080/135986 $\underline{6 \times .2020 .1752051}$

Corbera, E., Anguelovski, I., Honey-Rosés, J. y Ruiz-Mallén, I. (2020). Academia in the time of COVID-19: Towards an ethics of care. Planning Theory \& Practice, 21(2), 191-199. https://doi. org/10.1080/14649357.2020.1757891

Mohmmed, A. O., Khidhir, B. A., Nazeer, A. y Vijayan, V. J. (2020). Emergency remote teaching during Coronavirus pandemic: The current trend and future directive at Middle East College Oman. Innovative Infrastructure Solutions, 5(3), 1-11. https://doi.org/10.1007/ s41062-020-00326-7 